\title{
The risk of type 2 diabetes in the native population of highlands Aksay of Kyrgyzstan
}

\author{
Marina S. Moldobaeva, Anastasiya V. Vinogradova, Cholpon A. Muratova \\ Department of Propedeutic Therapy with Course on Endocrinology, Kyrgyz State Medical Academy named after \\ I.K. Akhunbaev, Bishkek, Kyrgyzstan
}

\begin{abstract}
Objective: Highlands Aksay of Naryn region of Kyrgyzstan has specific natural and climatic conditions and located at altitude of $3000 \mathrm{~m}$ above sea level. We aimed to study 10-years risk of type 2 diabetes (T2DM) in the native population of highlands Aksay of Naryn Region of Kyrgyzstan.

Methods: Overall, 152 indigenous people (50 men and 102 women) of highlands Aksay of Naryn region (3260-3680 $\mathrm{m}$ ) were studied using one-step sampling. The study was random, subjected to the conditions of singleness and territoriality. FINDRISC questionnaire was used to calculate the risk of T2DM.

Results: Women of highlands Aksay had a significantly higher prevalence of waist circumference (WC) $>80 \mathrm{~cm}$, body mass index $(\mathrm{BMI})>25 \mathrm{~kg} / \mathrm{m}^{2}$ and irregular intake of fruits and vegetables, whereas men showed irregular intake of fruits and vegetables, $B M I>25 \mathrm{~kg} / \mathrm{m}^{2}$, and $\mathrm{WC}>94 \mathrm{~cm}$.

Conclusion: The features of the 10-year-old risk of developing T2DM in the indigenous people of the highlands of Kyrgyzstan include the predominance of abdominal obesity and the irregular intake of fruits and vegetables. When stratifying the risks of developing T2DM, low risk predominates, and a very high risk does not occur. The prognosis of the indigenous people of the highlands of Kyrgyzstan regarding the risk of developing T2DM depends on phenotypic factors and living conditions in the highlands, with hypoxia playing the leading role. Among the mountain people of Kyrgyzstan, metabolic factors are dominated by abdominal obesity and, probably, to reduce the risks of developing diabetes, along with the fight against other negative factors, regular intake of vegetables and fruits is effective.
\end{abstract}

Key words: high-altitude, risk of diabetes type 2, native population, low risk

(Heart Vess Transplant 2020; 4; doi: 10.24969/hvt.2020.181)

\section{Introduction}

Three quarters of Kyrgyzstan territory are mountains, where a human is exposed to a full complex of hazardous conditions, of which hypoxia is the leading and most important one $(1,2)$. Highlands Aksay of Naryn region have specific natural and climatic conditions and located at altitude of $3000 \mathrm{~m}$ above sea level, with a population of 500 inhabitants. Lowaltitude Chui valley of Chui Region is located at altitude of 500-1300 m above sea level, and in 2015 its total population was 870300 .
Kyrgyzstan is a developing country (3-6). When analyzing selected studies, we found that in South Asian population type 2 diabetes mellitus (T2DM) develops in lower body mass index (BMI) range, compared to European Caucasians (7-16). In the age range of 20-79 years, national prevalence in the country was $5.2 \%$, comparative prevalence $6.3 \%$, number of adults with undiagnosed T2DM was 97.4 per 1000, and mortality from T2DM was 2560.3 (4). Because every other T2DM case remains undiagnosed in the world (4), timely T2DM risk detection will entail cardiovascular (CV) risk drop in future $(17,18)$.

Address for Correspondence: Marina S. Moldobaeva, Department of Propedeutic Therapy with Course on Endocrinology, Kyrgyz State Medical Academy named after I.K. Akhunbaev, Bishkek, Kyrgyzstan;

Email: moldobaeva_m@mail.ru

Received: 28.06.2019 Revised: 9.12.2019 Accepted: 12.12.2019

Copyright@ 2020 Heart, Vessels and Transplantation 
Such CV mortality indicators as increased cholesterol, systolic blood pressure (BP) and smoking were 3 times more prevalent in T2DM patients compared to healthy adults, sinceT2DM is a risk factor for CV diseases (19-21).Therefore, the overall CV risk (CVR) stratification in T2DM patients is germane, especially considering that in $20-30 \%$ of T2DM patients their CV complications are diagnosed already when diabetes is detected for the first time(19-27).

Studies haves shown that in high-altitude dwellers, blood sugar level is lower compared to low-altitude residents, and there was no single diabetes patient found above $3000 \mathrm{~m}$. In all age groups of high-altitude residents, obesity is 3 times less prevalent compared to low-altitude dwellers, 5(1)\% and $18(1) \%$ accordingly $(p<0.01)$.Other risk factors of T2DM are also less prevalent $(1,28,29)$.

Woolcott et al. (30-32) also demonstrated an inverse relationship between height and obesity and better glucose control at high altitudes. Conversely, a study conducted in the high and low mountains of Peru suggests a higher incidence of T2DM at high altitude compared to low altitude. It is important to note that T2DM there is largely due to obesity (33). The relationship between obesity and T2DM is well known even in children (34). Recently, Hirschler et al. (35) reported a higher risk of T2DM in Argentinean indigenous children living at 3750 meters compared to children living at 1400 meters. The relationship between saturation of oxyhemoglobin at altitude and the development of metabolic syndrome and T2DM is also known (36).

Despite higher detectability in high-altitude Naryn region and middle-altitude Issyk-Kul region compared to admission levels, detectability of T2DM is still lower compared to middle-altitude Issyk-Kul region (by 2.7 and 3.0 times accordingly) (37). Therefore, studying risk factors of T2DM in the indigenous population of high-altitude regions of Kyrgyzstan in order to produce evidence-based recommendations taking in account mountainous climate to prevent T2DM is pertinent.

Objective: to study 10-years risk of diabetes type 2 in the indigenous residents of highlands Aksay of Naryn Region of Kyrgyzstan.

\section{Methods}

\section{Population and design}

Using a single-stage territorial sampling, 152 indigenous people of the highlands Aksay of the Naryn region (3260-3680 m) were examined. Indigenous people are people who have been living permanently in this territory since birth. Of these, men - 50, women - 102. Overall, 177 residents of low-altitude Chui valley of Chui region were studied as controls, of whom 56 were men and 121 women. The study was cross-sectional and random, subjected to the conditions of singleness and territoriality and we randomized subjects in regions and sex. Inclusion criteria were age 18 - 70 years, indigenous people. Exclusion criteria were patients with an established diagnosis of T2DM, non-indigenous residents with severe conditions, children under 18 years of age. Study period: May 1 - August 30, 2017.

This study was approved by KSMA bioethics committee. Each subject in this study provided informed consent to participate.

\section{Characteristics of altitudes}

In the highlands Aksay, our study was conducted because it is the only high-altitude region in Kyrgyzstan in which the indigenous population lives and works. In comparison with the low-altitude region, the duration of winter is longer, and dwelling and nutrition are associated with a more severe climate in high-altitudes; therefore, we studied the highlands Aksay and compared it with the lowlands Chui. Other regions have low and medium altitudes. Therefore, a comparison of the 10-year risk of developing T2DM was carried out by us in the Aksay high-altitude and Chui low-altitude regions.

\section{FINDRISC questionnaire to determine T2DM risk}

We used FINDRISC questionnaire to determine T2DM risk, which considers age, BMI, waist circumference (WC), physical activity, regular intake of fruits and vegetables, regular use of antihypertensive medications and family history of the disease. Obesity was diagnosed using the formula: body mass $(\mathrm{kg}) /$ height $(\mathrm{m})^{2} \quad(\mathrm{WHO}, 1995)$. Subjects with BMI exceeding $25 \mathrm{~kg} / \mathrm{m}^{2}$ were considered overweight. WC was measured on a midpoint of the distance between the costal arch and the iliac crest. Abdominal obesity (AO) was diagnosed when WC exceeded $94 \mathrm{~cm}$ in men and $80 \mathrm{~cm}$ in women (FINDRISC). The FINDRISC questionnaire was developed by the Finnish Diabetes Association - FINnish Diabetes Risk SCore (FINDRISC) to assess the 10-year risk of T2DM in adults (38). 
A one-time, individual, full-time questionnaire survey was used. No walking or physical activity for less than 30 min a day was treated as low physical activity. The risk was classified using the following grading approach: less than 7 - low risk; 7-11 -moderate risk; 12-14 medium risk; 15-20 - high risk; more than 20 very high risk $(27,39-41)$.

\section{Statistical analysis}

We used online calculator for statistical analysis (42). In this cross-sectional study, we used descriptive statistics and calculated prevalence rate (PR) of risk factors for T2DM and 95\% confidence interval (Cl).

\section{Results}

\section{Risk factors of T2DM in female population}

In the group of women, the frequency of the BMI risk factor above $25 \mathrm{~kg} / \mathrm{m}^{2}$ is lower in the highlands Aksay (55.9\%) ( $p<0.05, \mathrm{PR} 0.56, \mathrm{Cl} 0.46-0.66)$ than in the lowlands Chui (62\%) ( $p<0.05$, PR 0.62, Cl 0.53-0.71), regardless of age. In the same group, the frequency of the risk factor $W C>80 \mathrm{~cm}$ is lower in the high altitudes $(80.38 \%)(p<0.05, P R 0.80, \mathrm{Cl} 0.72-0.88)$ than in the low altitudes (81.4\%) ( $p<0.05$, PR $0.81, \mathrm{Cl} 0.74-0.88)$, mainly under the age of 55 years in both groups (26.58\% and $42.7 \%$, respectively). An active lifestyle is also lower in the highlands Aksay (74.6\%) $(p<0.05$, PR $0.74, \mathrm{Cl} 0.66-0.82)$ than in the lowlands Chui (84.5\%) $(p<0.05, P R \quad 0.84, \mathrm{Cl} 0.78-0.9)$, mainly under the age of 45 years in both groups $(25.4 \%$ and $46.9 \%$, respectively), with increasing age, activity decreases. The frequency of the risk factor as the irregular consumption of fruits and vegetables was also lower in the high-altitudes $(40.2 \%)(p<0.05, P R \quad 0.40, \mathrm{Cl} 0.31$ $0.49)$ than in the low-altitudes $(56.3 \%)(p<0.05, \mathrm{Cl}$ $0.47-0.65)$, regardless of age.

The regular intake of antihypertensive drugs was lower in the highlands Aksay (5.5\%) ( $p<0.05$, PR 0.56, $\mathrm{Cl} 0.02-0.10)$ than in the lowlands Chui $(7.8 \%)(p<0.05$, $\mathrm{Cl}$ 0.03-0.13) and increases with age.

In the highlands, high blood glucose in history (e.g. determined during a health examination, during an illness, during pregnancy) had 4 people (2.6\%), of which 3 were women $(2.9 \%$ among all women) (PR $0.03, \mathrm{Cl} 0-0.06), 1$ male ( $2 \%$ among all men) (PR 0.02, $\mathrm{Cl}-0.02-0.06)$. In the lowlands Chui, there are 6 people (3.4\%) with history of high blood glucose level, of which: women - 4 (3.3\% among all women) (PR 0.03, $\mathrm{Cl} 0-0.06)$, men - 2 (3.6\% among all men) (PR 0.03, $\mathrm{Cl}-$ 0.01-0.07). The indicators are not quite high both in the main groups and in the groups by gender, but with risk stratification, we considered them in conjunction with other risk factors. The frequency of the risk factor as a family history of T2DM is higher in the highlands Aksay (15.7\%) than in the Chui region (11.4\%) ( $p>0.05)$.

Thus, of all T2DM risk factors in women, $W C>80 \mathrm{~cm}$ was significantly most prevalent, both in highlands Aksay (80.38\%) and lowlands Chui (81.4\%), followed by $\mathrm{BMI}>25 \mathrm{~kg} / \mathrm{m}^{2}$ (55.9\% and $62 \%$ accordingly), and irregular intake of fruits and vegetables $(40.2 \%$ and $56.3 \%$ accordingly) and intake of antihypertensive medications (5.5\% and 7.8\%, respectively) (Fig.1).

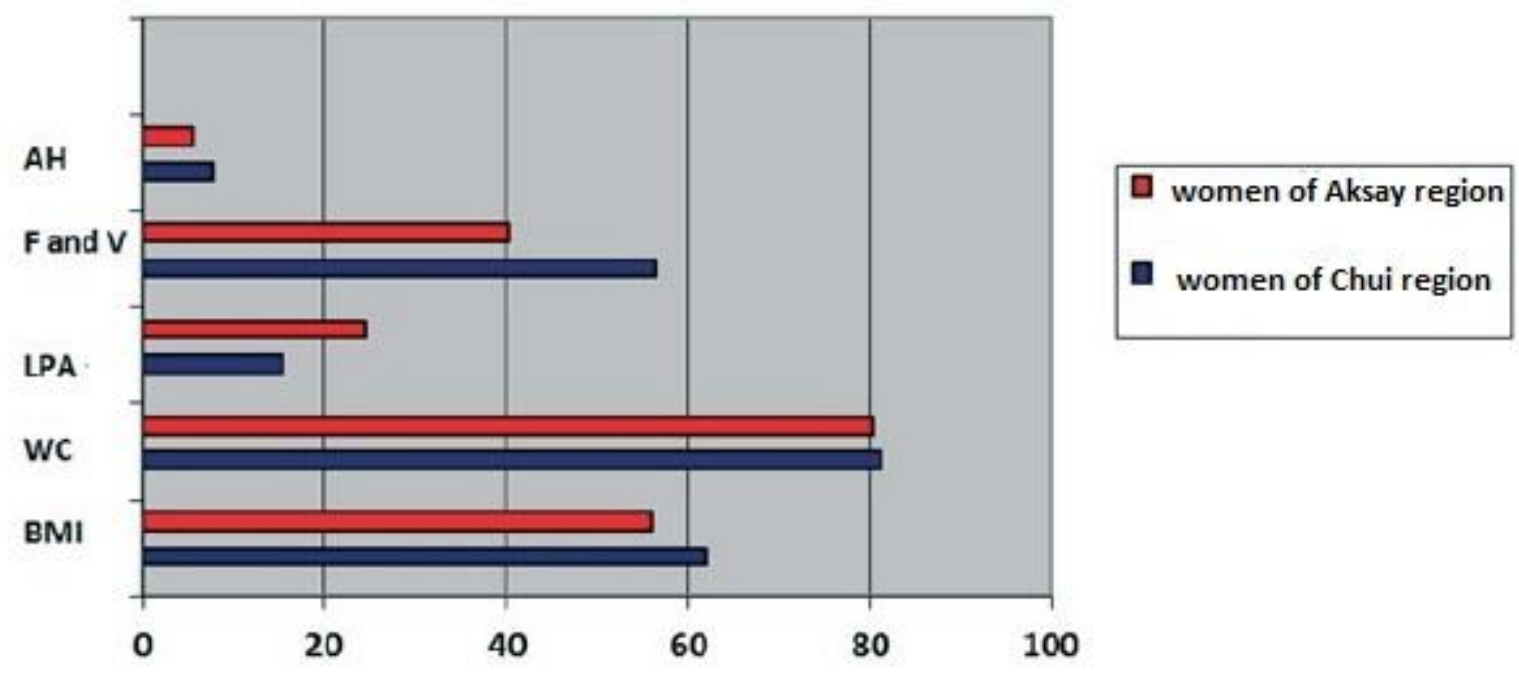

Figure 1. Comparative prevalence of risk factors in indigenous female residents of highlands Aksay and lowlands Chui

$\mathrm{AH}$ - regular use of antihypertensive medications, $\mathrm{BMI}$ - body mass index, $\mathrm{F}$ and $\mathrm{V}$ - irregular intake of fruits and vegetables, LPA - low physical activity, WC - waist circumference 


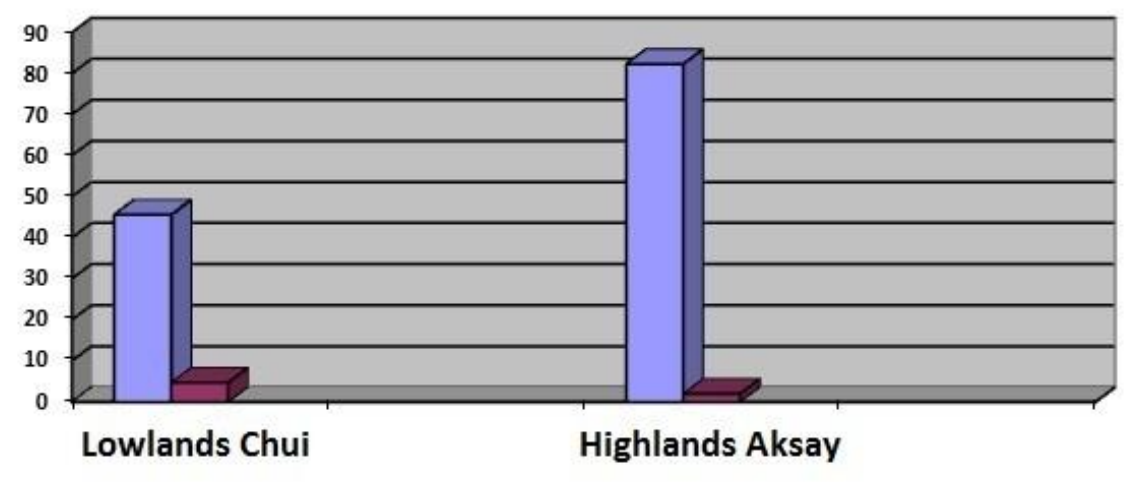

Figure 2. Comparative prevalence of diabetes risk factors in indigenous female residents of highlands Aksay and lowlands Chui

Women have a predominantly low risk of developing diabetes, both in the high altitudes (82.3\%) (PR 0.82, $\mathrm{Cl}$ 0.75-0.89) and in the low altitudes (45.6\%) (PR 0.45, $\mathrm{Cl} 0.36-0.54$ ) (Fig. 2). Very high risk was not detected.

\section{Risk factors of T2DM in male population}

In the group of men, the frequency of the BMI risk factor above $25 \mathrm{~kg} / \mathrm{m}^{2}$ is lower in the high-altitude residents (26\%) ( $\mathrm{p}<0.05$, PR 0.26, $\mathrm{Cl} 0.14-0.38)$ than in the residents of low altitudes $(46.2 \%) \quad(p<0.05, P R$ $0.46, \mathrm{Cl} 0.33-0.59$ ), mainly under the age of 55 years (22\% and $23.3 \%$, respectively).

The risk factor frequency WC $>94 \mathrm{~cm}$ is lower in the highlands Aksay (22.4\%) ( $p<0.05$, PR $0.22, \mathrm{Cl} 0.11$ $0.33)$ than in the Chui region (45.3\%) $(p<0.05$, PR 0.45, $\mathrm{Cl} 0.32-0.58$ ), mainly at the age of less than 55 years (20.3\% and $14.9 \%$, respectively), decreases with age.

An active lifestyle is higher in the high altitudes (94\%) (PR 0.94, $\mathrm{Cl}$ 0.88-1.0) than in the low altitudes (88.3\%) $(p<0.05, P R 0.83, \mathrm{Cl} 0.78-0,96)$, mainly at the age of less than 55 years ( $87 \%$ and $71.3 \%$ respectively), decreases with age. In our opinion, this is due to the fact that in the highlands men are engaged in cattle breeding all year round.

Irregular consumption of fruits and vegetables is lower in the highlands Aksay (48.8\%) ( $p<0.05$, PR $0.48, \mathrm{Cl} 0.35-0.61$ ) than in the Chui region (100\%) ( $p$ $<0.05, \mathrm{PR} 1, \mathrm{Cl} 1$ ), decreases with age.

The regular intake of antihypertensive drugs in the group of men is lower in the highlands $(6 \%)(p<0.05$, PR 0.06, Cl 0-0.12) than in the low mountains (10.7\%) ( $p<0.05$, PR $0.11, \mathrm{Cl} 0.03-0.19$ ), regardless of age. In the same group, the frequency of the risk factor family history of T2DM is relatively higher in the high altitudes (8\%) than in the low altitudes (7\%), more at the age of 55 years, which decreases with age.

Thus, T2DM risk factors in men living in highlands Aksay were grouped as follows: irregular fruits and vegetables intake $(48.8 \%), B M I>25 \mathrm{~kg} / \mathrm{m}^{2}(26 \%)$, followed by WC> $94 \mathrm{~cm}$ (22.4\%). In lowlands Chui, irregular intake of fruits and vegetables was also a leading risk factor (100\%), followed by $\mathrm{BMI}>25 \mathrm{~kg} / \mathrm{m}^{2}$ (46.2\%) and WC>94 cm (45.3\%). All these risk factors prevailed in the age group below 55 and lessened in both regions with age (Fig.3). 


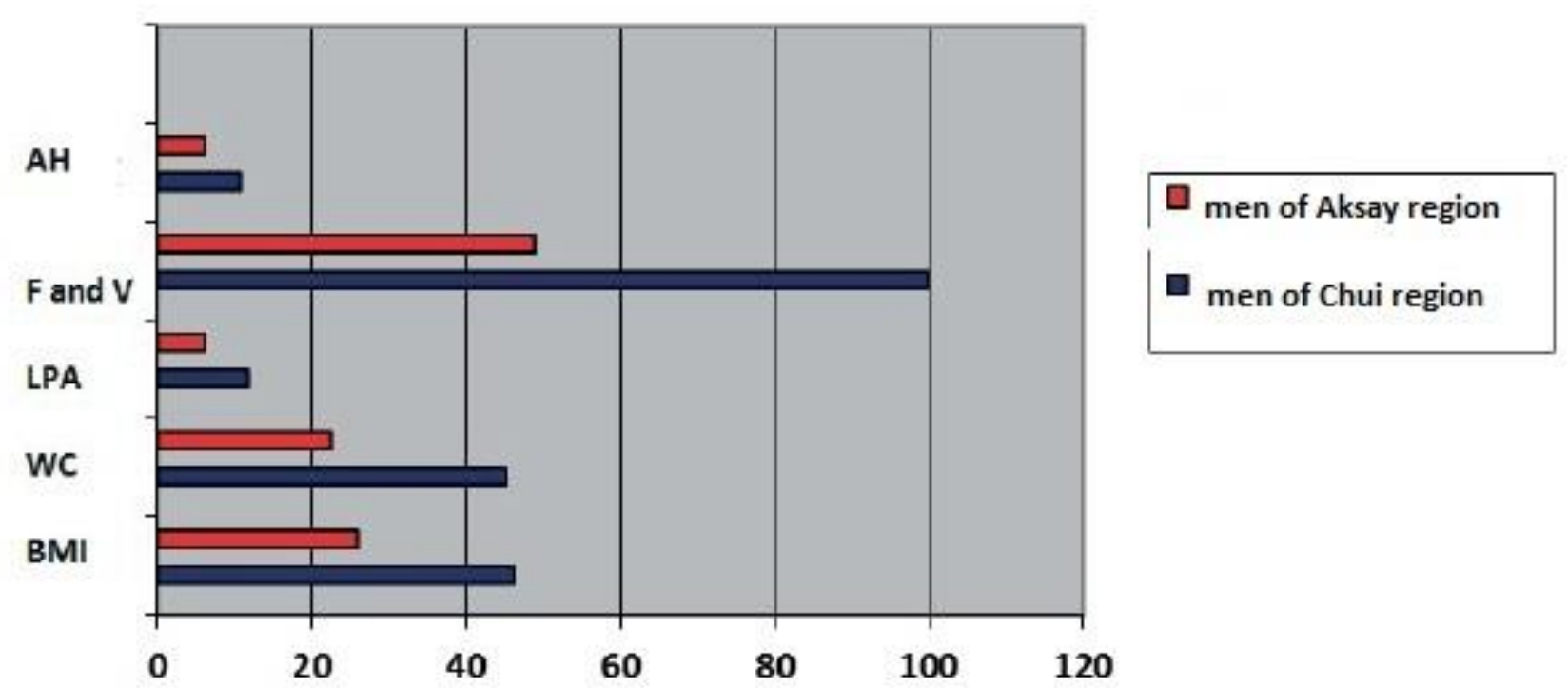

Figure 3. Comparative prevalence of risk factors in indigenous male residents of highlands Aksay and lowlands Chui

$\mathrm{AH}$ - regular use of antihypertensive medications, $\mathrm{BMI}$ - body mass index, $\mathrm{F}$ and $\mathrm{V}$ - irregular intake of fruits and vegetables, LPA - low physical activity, WC - waist circumference

In men living in highlands Aksay as well as in lowlands Chui, the leading risk level was low- 64\% (PR 0.64, Cl
0.51-0.77) and 69\% (PR 0.7, Cl 0.58-0.82) accordingly. There was no very high risk (Fig. 4).

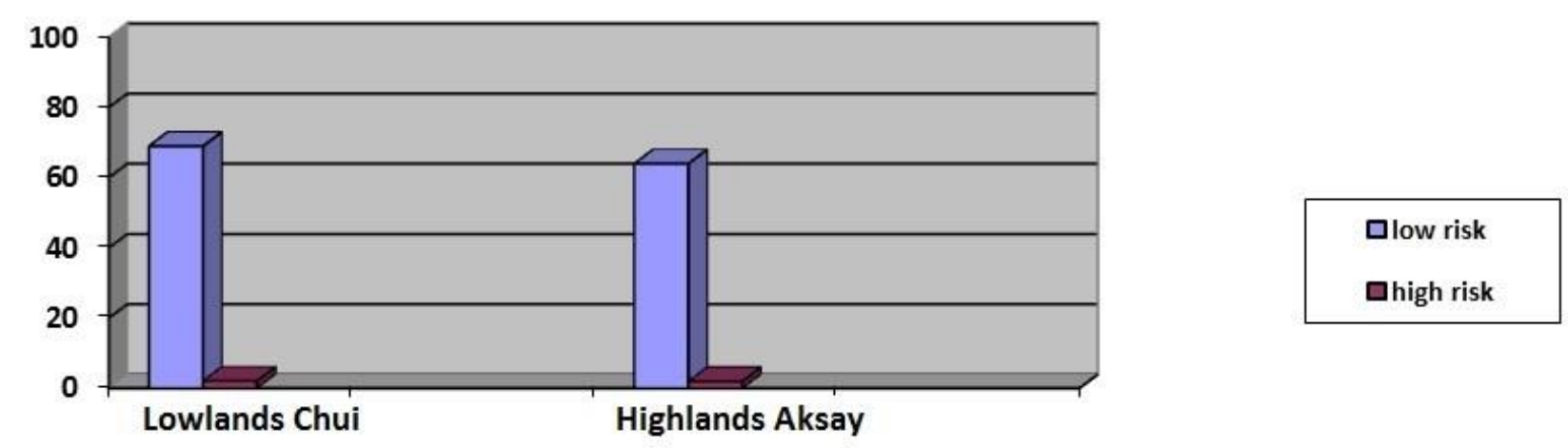

Figure 4. Comparative prevalence of diabetes risk factors in indigenous male residents of highlands Aksay and lowlands Chui

\section{Discussion}

The question of whether growth and / or residence in high mountain regions are risk factors for the development of T2DM remains a matter of discussion (43). Earlier, we in the Kyrgyz population studied the 10-year risk of developing T2DM higher among residents of low altitudes compared to high altitudes (44). We did not identify any high-risk groups among residents with a low or high incidence of disease. The leading FINDRISC composites are elevated levels of WC and BMI, possibly due to irregular consumption of fruits and vegetables, which depend on altitude of residence and age (44). 
Among the highlands Aksay and lowlands Chui populations surveyed by us, the factors of the 10 -year risk of developing T2DM, depending on the place of residence and gender, have their own characteristics. Of the metabolic phenotypes of the 10-year risk of developing T2DM in the indigenous population of the high-altitudes and low-altitudes of Kyrgyzstan, there are 3 main risk factors. Of these, according to the frequency of occurrence, the following were identified: in the first place, $W C>80 \mathrm{~cm}$, then $\mathrm{BMI}>25$ $\mathrm{kg} / \mathrm{m}^{2}$ and irregular intake of vegetables and fruits in women; in men, irregular consumption of fruits and vegetables comes first, followed by BMI> $25 \mathrm{~kg} / \mathrm{m}^{2}$ and $W C>94 \mathrm{~cm}$.

Risk factor arterial hypertension was much less common. It is definitely difficult to answer. Despite the fact that arterial hypertension is closely associated with salt intake and obesity, prolonged exposure to low atmospheric pressure and hypoxia in indigenous highlanders leads to a decrease in the incidence of arterial hypertension. The highlanders' organism has high risks of a reflex effect of the pulmonary circulation on systemic circulation and the development of pulmonary arterial hypertension and other adaptive mechanisms for living in the mountains (1). There are conclusions on arterial hypertension in high altitudes, which contradict this. Systemic blood pressure, cholesterol (total and low-density lipoprotein) and glucose levels were higher in highaltitude children, but at least based on mean (SD) values, these levels were normal: mean systolic blood pressure was 87 (14) $\mathrm{mmHg}$ (35) compared with 100 $\mathrm{mmHg}$ as the 50th percentile of systolic blood pressure in the same age group of the control group (46). Higher blood pressure values are associated with lower temperature at high altitude (a decrease of $6.5^{\circ}$ $\mathrm{C}$ per $1000 \mathrm{~m}$ ) due to cutaneous vasoconstriction (46). In low-altitude and high-altitude, women reliably had high prevalence of WC $>80 \mathrm{~cm}(81.4 \%$ and $80.38 \%$ respectively), then $\mathrm{BMI}>25 \mathrm{~kg} / \mathrm{m}^{2}(62 \%$ and $55.9 \%$ respectively), then irregular intake of vegetables and fruits ( $56.3 \%$ and $40.2 \%$ respectively). Risk factors are expressed at the age of 55 years and older in the highlands Aksay ( $p>0.05)$, in the lowlands Chui - under the age of 55 years $(p<0.05)$. Risk factors among men are distributed in a slightly different way: in low altitudes and high altitudes, irregular consumption of fruits and vegetables $(100 \%$ and $48.8 \%$ ) comes first, followed by $\mathrm{BMI}>25 \mathrm{~kg} / \mathrm{m}^{2}$ (46.2\% and $26 \%)$ and $W C>94 \mathrm{~cm}(45.3 \%$ and $22.4 \%$ respectively). Risk factors are expressed at the age of less than 55 years in both regions $(p<0.05)$. Although we did not set the goal of our study to study the dependence of risk factor on age, we suggest the high incidence of increased $\mathrm{BMI}$ and abdominal obesity in men of working age under 55 years of age in low altitudes and high altitudes.

Compared with other studies, our data on the prevalence of increased BMI in low altitudes in men ( $28 \%$ and $19.1 \%$ vs $46.2 \%$ and $26 \%$, respectively), in women $(41 \%$ and $30.5 \%$ vs $62 \%$ and $55.9 \%$ respectively); the prevalence of abdominal obesity in the low-altitudes among men $(33.5 \%$ and $21.6 \%$ vs $45.3 \%$ and $22.4 \%$, respectively) and among women ( $73.7 \%$ and $57 \%$ vs $81.4 \%$ and $80.38 \%$, respectively); the prevalence of hypertension: in men it is low both in low altitudes (4.6\%) and in high altitudes (10.7\%), in women also there is a low hypertension rate $7.8 \%$ and $5.5 \%$, respectively, confirm data of previous study (22). Frequency of hypertension in low-altitude and high-altitude among men and women is not marked, increased with increasing age in women in both regions.

The main risk factor in the high-altitudes for men is the irregular consumption of fruits and vegetables, and for women - abdominal obesity. When comparing the incidence rate of increased BMI and abdominal obesity in men and women, these risk factors were higher in low altitudes under 55 years of age. This once again confirms that insulin resistance plays a major role in the development of T2DM. In highaltitude conditions, the development of insulin resistance is apparently reduced due to environmental factors, of which due to hypoxia among other metabolic risk factors. Changes in insulin resistance are adaptive in nature and this issue has not been fully studied (47-50). Hirschler et al. presented interesting clinical and metabolic characteristics for a relatively large sample of schoolchildren - residents of varying altitudes. In addition to metabolic risk factors, the HOMA-IR value turned out to be less than the threshold level of 3.16 for children living at high and low altitudes, i.e., the risk of developing diabetes in children in low altitudes and high altitudes is reduced $(35,51)$.

The peculiarity was that these risk factors were identified at working age in our populations, which is possibly associated with the characteristics of housekeeping and the nature of labor, nutrition in low and high altitudes, the distribution of fat in deep subcutaneous layers in Asians and the influence of the mountain climate.

The risk factor as a history of high blood glucose in the high altitudes $(2.6 \%)$ is lower than in the low altitudes (3.4\%). 
The frequency of occurrence of 2 or more risk factors is very low (7\%), stratification revealed a predominance of low risk regardless of the region of residence and gender, a very high risk does not occur.

Study limitations: The main study limitation is that risk factors were determined only using a questionnaire. Larger epidemiological studies are needed to confirm these findings.

Conclusion: The features of the 10-year-old risk of developing T2DM in the indigenous people of the high-altitudes of Kyrgyzstan include the predominance of abdominal obesity and the irregular intake of fruits and vegetables. When stratifying the risks of developing T2DM, low risk predominates, and a very high risk does not occur. The prognosis of the indigenous people of the high-altitudes of Kyrgyzstan regarding the risk of developing T2DM depends on phenotypic factors and living conditions in the high altitudes, with hypoxia playing the leading role. Among the highlanders of Kyrgyzstan, metabolic factors are dominated by abdominal obesity, and it is likely that regular intake of fruits and vegetables is effective to reduce the risks of developing diabetes, along with the fight against other negative factors.

Peer-review: External Conflict of interest: None to declare Authorship: M.S.M, A.V.V. and Ch.A.M. are equally contributed the study and preparation of manuscript Acknowledgments and funding: None to declare

\section{References}

1.Mirrahimov M, Meimanaliev T. Alpine cardiology 1984: Essays: 316.

2.Sooronbaev T. Clinical and functional characteristics of chronic obstructive pulmonary disease in high mountains and approaches to its therapy. Abstract Doct Diss 2007; 45p.

3.WHO Global Diabetes Report. 2016.

4.International Diabetes Federation "Diabetes Atlas $7^{\text {th }}$ edition" 2015.

5.Chiu A. Deriving ethnic-specific BMI cutoff points for assessing diabetes risk. Diabetes Care 2011; 34:17418.

6.Butler W, Ostrander L, Carman W, Lamphiear D. Mortality from coronary heart disease in the Tecumsech Study. Long-term effect of diabetes mellitus, glucose tolerance and other risk factors. Am J Epidemol1985; 121:541-7.

7.Webb D, Khunti K, Chatterjee S. Adipocytokine associations with insulin resistance in British South Asians. J Clin Endocrinol Metab 2006; 78: 2356-60.

8.Petersen K, Dufour S, Feng J. Increased prevalence of insulin resistance and nonalcoholic fatty liver disease in Asian Indian men. PNAS 2013; 103:18273-7. 9.Goldstein B, Scalia R. Adiponectin: a novel adipokine linking adipocytes and vascular function. J Clin Endocrinol Metab 2004; 89: 2563-8.

10.Kodama K, Tojjar D, Yamada S, Toda K, Patel CJ, Butte AJ. Ethnic differences in the relationship between insulin sensitivity and insulin response: $A$ systematic review and meta-analysis. Diabetes Care 2013; 36: 1789-96.

11.Sniderman A. Why might South Asians be so susceptible to central obesity and its atherogenic consequences? The adipose tissue overflow hypothesis. Int J Epidemiol 2007; 36: 220-5.

12.Banerji MA, Faridi N, Atluri R, Chaiken RL, Lebovitz $\mathrm{H}$. Body composition, visceral fat, leptin, and insulin resistance in Asian Indian men. J Clin Endocrinol Metab 1999; 84:137-44.

13.Indulekha K, Anjana RM, Surendar J, Mohan V. Association of visceral and subcutaneous fat with glucose intolerance, insulin resistance, adipocytokines and inflammatory markers in Asian Indians (CURES113).Clin Biochem 2011; 44: 281-7.

14.Anand M, Tarnopolsky S. Adipocyte hypertrophy, fatty liver and metabolic risk factors in South Asians: the Molecular Study of Health and Risk in Ethnic Groups (mol-SHARE).PLoS ONE 2011; 6: P.e22112

15.Balakrishnan P, Grundy S, Islam A, Dunn F, Vega $\mathrm{GL}$. Influence of upper and lower body adipose tissue on insulin sensitivity in South Asian men. J Invest Med 2012; 60: 999-1004.

16. Bakker LE, van Schinkel LD, Guigas B, Streefland TC, Jonker JT, van Klinken JB, et al. A 5-day high-fat, highcalorie diet impairs insulin sensitivity in healthy, young South Asian men but not in Caucasian men. Diabetes 2014; 63: 248-58.

17.World Atlas of Cardiovascular Disease Prevention and Control. WHO, Geneva, 2013.

18.Yusuf S, Hawken S, Ounpuu S, Dans T, Avezum A, Lanas $F$, et al. Effect of potentially modifiable risk factors associated with myocardial infarction in 52 countries (the INTERHEART Study): case-control study. Lancet 2004; 364: 937-52. 
19.The Multiple Risk Factor International Trial (MRFIT). A national study of primary prevention of coronary heart disease. JAMA1976; 235: 825-7.

20.Berliner J, Navab M, Fogelman AM, Frank JS, Demer LL, Edwards PA, et al. Atherosclerosis: Basic mechanisms, oxidation, inflammations, and genetics. Circulation 1995; 91: 2488-96.

21.Ametov A, Sokareva E. Disorders of lipid metabolism in type 2 diabetes mellitus and their correction. Breast Cancer 2009; 17: 1586-90.

22. Mirrakhimov E. Prevalence of obesity and cardiovascular risk factors in the population of low, moderate and high altitude regions of Kyrgyzstan (preliminary results). Available at URL: http: //omicsgroup.com/conferences/cardiology-2013.

23.Gans R, Donker A. Insulin and blood pressure regulation. J Intern Med 1991; 229: 49-64.

24.Pyorala K, Pederson TR, Kjekshus J, Faergeman O, Olsson AG, Thorgeirsson G, et al. for the Scandinavian Simvastatin Survival Study (4S) Group. Cholesterol lowering with simvastatin improves prognosis of diabetic patients with coronary artery disease: a subgroup analysis of the Scandinavian Simvastatin Survival Study (4S).Diabetes Care 1997; 20: 614-20. 25.International Diabetes Federation "Diabetes Atlas $6^{\text {th }}$ edition" 2014.

26. Global atlas on cardiovascular disease prevention and control. WHO 2013.

27.Eckel R, Cornier M. Update on the NCEPATR-III emerging cardiometabolic risk factors. BMC Med 2014; 26: 115.

28. Kalyuzhny I. Actual problems of endocrinology. Abstracts of the IV Republican Scientific and Practical Conference of Endocrinologists of the Kyrgyz SSR. 1983; 4-8.

29. Moldobaeva M. Features of the distribution, clinical and functional manifestations, prevention and treatment of obesity and type II diabetes mellitus in residents of the low mountains $(760-1200 \mathrm{~m})$ and high mountains (2040-3500 m) Tien Shan. Abstract Doct Diss1993; 31p.

30.Woolcott O, Castillo O, Gutierrez C, Elashoff RM, Stefanovski D, Bergman RN. Inverse association between diabetes and altitude: a cross-sectional study in the adult population of the United States. Obesity (Silver Spring) 2014; 22: 2080-90.

31. Woolcott O, Ader M, Bergman R. Glucose homeostasis during short-term and prolonged exposure to high altitudes. Endocr Rev 2015; 36: 14973.

32. Woolcott O, Gutierrez C, Castillo O, Elashoff RM, Stefanovski D, Bergman RN. Inverse association between altitude and obesity: A prevalence study among Andean and low-altitude adult individuals of Peru. Obesity (Silver Spring) 2016; 24: 929-37.

33.Bernabé-Ortiz A, Carrillo-Larco R, Gilman R, Miele $\mathrm{CH}$, Checkley W, Wells JC, et al. Geographical variation in the progression of type 2 diabetes in Peru: The CRONICAS Cohort Study. Diabetes Res Clin Pract 2016; 121: 135-45.

34.Pulgaron ER, Delamater AM. Obesity and type 2 diabetes in children: epidemiology and treatment. Curr Diab Rep 2014; 14: 508.

35. Hirschler V, Maccallini G, Molinari C, Hidalgo M, Intersimone P, Gonzalez C. Type 2 diabetes markers in indigenous Argentinean children living at different altitudes. AIMS Public Health 2018; 5: 440-53.

36. Miele C, Schwartz A, Gilman R, Pham L, Wise RA, Davila-Roman VG. et al. Increased cardiometabolic risk and worsening hypoxemia at high altitude. High Alt Med Biol 2016; 17: 93-100.

37. Moldobaeva $M$, Narkulova G, Vinogradova $A$, Egemberdieva B, Tologonov B, Sagyndykova N, et al. The prevalence of type 2 diabetes in the Issyk-Kul and Naryn regions of Kyrgyzstan. Journal of the KSMA 2017; 2: 53-6.

38.Lindstrom J, Tuomilehto J. The diabetes risk score: A practical tool to predict type 2 diabetes risk.

Diabetes Care 2003; 26: 725-31.

39.Bang $H$, Edwards A, Bomback A, Ballantyne C, Brillon $D$, Callahan $M$, et al. Development and validation of a patient self-assessment score for diabetes risk. Intern Med 2009; 151: 775-83.

40.Saaristo T, Peltonen M, Lindström J, Saarikoski L, Sundvall J, Eriksson J, et al. Cross-sectional evaluation of the Finnish Diabetes Risk Score: a tool to identify undetected type 2 diabetes, abnormal glucose tolerance and metabolic syndrome. Diab Vasc Dis Res 2005; 2: 67-72.

41.Nightingale C, Rudnicka A, Owen C. Influence of adiposity on insulin resistance and glycemia markers among U.K. children of South Asian, Black AfricanCaribbean, and White European origin: Child Heart and Health Study in England. Diabetes Care 2003; $36: 1712-9$. 
42.http://medstatistic.ru/calculators/calchi.html

43.Burtscher M, Gatterer H, Burtscher J. Does growing up in high altitude pose a risk factor for type 2 diabetes? AIMS Public Health 2019; 6: 96-8.

44.Moldobaeva MS, Vinogradova AV, Esenamanova MK. Risk of type 2 diabetes mellitus development in the native population of low and high-altitude regions of Kyrgyzstan: Finnish Diabetes Risc score questionnaire results. High Alt Med Biol 2017; 18: 428-35.

45. National High Blood Pressure Education Program Working Group on High Blood Pressure in Children and Adolescents. The fourth report on the diagnosis, evaluation, and treatment of high blood pressure in children and adolescents. Pediatrics 2004; 114: 55576.

46. Burtscher $M$, Burtscher J. Blood pressure and hypertension in people living at high altitude. Hypertens Res. In press.

47.Bonora E, Kiechl S, Willeit J, Oberhollenzer F, Egger $G$, Targher $G$, et al. Prevalence of insulin resistance in metabolic disorders: the Bruneck Study. Diabetes1998; 47: 1643-9.

48.Schwarzburd PM. Different faces of insulin resistance. CHEMISTRY AND LIFE. BIOLOGY, MEDICINE 2013; 7.

49. Kvitkova L, Yelenskaya T, Blagoveshchenskaya $O$. Insulin resistance and factors determining it. Siberian Medical Journal 2008; 5:12-6.

50. Makisheva R. The adaptive value of signs of insulin resistance. Astana Medical Journal 2007; 3: 137-9.

51.Keskin M, Kurtoglu S, Kendirci M, Atabek ME, Yazici C. Homeostasis model assessment is more reliable than the fasting glucose/insulin ratio and quantitative insulin sensitivity check index for assessing insulin resistance among obese children and adolescents. Pediatrics 2005; 115: 500-3. 